\title{
The impact of the bone marrow microenvironment on multiple myeloma (Review)
}

\author{
JIANHAO HOU ${ }^{1,2^{*}}$, RONGFANG WEI ${ }^{2 *}$, JINJUN QIAN $^{2}$, RONGGEN WANG $^{2}$, \\ ZHIMIN FAN ${ }^{1}$, CHUNYAN GU ${ }^{1,2}$ and YE YANG $^{2,3}$ \\ ${ }^{1}$ National Medical Centre of Colorectal Disease, The Third Affiliated Hospital of Nanjing University \\ of Chinese Medicine, Nanjing, Jiangsu 210001; ${ }^{2}$ School of Medicine and Life Sciences, \\ Nanjing University of Chinese Medicine; ${ }^{3}$ School of Holistic Integrative Medicine, \\ Nanjing University of Chinese Medicine, Nanjing, Jiangsu 210023, P.R. China
}

Received April 17, 2019; Accepted July 10, 2019

DOI: $10.3892 /$ or.2019.7261

\begin{abstract}
Multiple myeloma (MM) is characterized by the accumulation of monoclonal plasma cells in the bone marrow (BM). The interaction between the BM microenvironment and MM plasma cells can influence cell proliferation, drug resistance and prognosis of the disease. The BM microenvironment (BMME) consists of a cellular and non-cellular compartment. The cellular compartment includes stromal cells, endothelial cells, osteoclasts and osteoblasts, and the non-cellular compartment includes the extracellular matrix (ECM) and the liquid milieu, which contains cytokines, growth factors and chemokines. The complex interaction between the BM microenvironment and MM plasma cells influences disease development and prognosis. The present review focuses on the interaction between malignant plasma cells and the BM microenvironment during MM progression. An improved understanding of the interaction between MM plasma cells and their microenvironment will enable the development of novel therapeutic tools that can be used in the treatment of MM, a currently incurable blood cancer.
\end{abstract}

Correspondence to: Dr Chunyan Gu, School of Medicine and Life Sciences, Nanjing University of Chinese Medicine, 138 Xianlin Road, Nanjing, Jiangsu 210023, P.R. China

E-mail: guchunyan@njucm.edu.cn

Dr Ye Yang, School of Medicine and Life Sciences, Nanjing University of Chinese Medicine, 138 Xianlin Road, Nanjing, Jiangsu 210023, P.R. China

E-mail: yangye876@sina.com

*Contributed equally

Key words: multiple myeloma, bone marrow, microenvironment, bone marrow stromal cell, osteoclast, osteoblast, interleukin-6, exosomes

\section{Contents}

1. Introduction

2. The bone marrow microenvironment

3. Conclusion

\section{Introduction}

Multiple myeloma (MM) is the second most common haematological malignancy worldwide. However, $\mathrm{MM}$ is incurable for the majority of patients (1). Malignant plasma cells expand in the bone marrow, in which they constantly develop, acquire resistance to apoptosis and eventually cause patients to exhibit symptomatic MM (CRAB: High calcium, renal impairment, anemia and bone lesions) (2). In most cases, MM is preceded by an asymptomatic premalignant disease known as monoclonal gammopathy of undetermined significance (MGUS) (3). It has been reported that $\sim 2 \%$ of the population over the age of 50 are affected by MGUS, with $1 \%$ of cases progressing to MM every year (4).

MM acts as osteolytic bone metastasis, and this behavior differs from that of other hemotologic malignancies that infiltrate the bone marrow. The bone marrow is a semi-solid tissue that occupies cavities within spongy or cancellous bone. Bone marrow is composed of interstitial cells and blood vessels that are associated with haematopoiesis, bone marrows primary function (5). The bone marrow microenvironment (BMME), which is also known as the bone marrow niche, consists of a cellular and non-cellular component. The cellular component includes stromal cells, endothelial cells, osteoclasts (OCs), osteoblasts (OBs) and immune system cells, and the non-cellular component includes the extracellular matrix (ECM) and liquid milieu, which contains chemokines, cytokines and growth factors (6). The BMME has been previously demonstrated to be a scaffold for haematopoietic stem and progenitor cells (HSPCs) (7-9). Further studies (10-12) have reported that the BMME serves an important role in haematopoiesis and in neoplastic disease. The stability of the BMME is essential for the maintenance of normal cell proliferation, differentiation, metabolism and mobilization. An abnormal BMME has been revealed to lead 
to cell lesions or tumorigenesis. An abundance of research has been undertaken into elucidating the biological features of $\mathrm{MM}$, and the association with the BMME $(13,14)$. It can be concluded from these studies that the BMME serves a key role in the differentiation, proliferation and drug resistance of malignant plasma cells. These studies also provide preclinical evidence that MM cells and bone marrow stromal cells (BMSCs) can be targeted as antitumor strategies and used in disease treatment (15). The present article elaborates on the complex interaction that exists between the BMME and MM.

\section{The bone marrow microenvironment}

\section{Cellular compartment}

Bone marrow stromal cells (BMSCs). The components of the BMME, especially the BMSCs and the extracellular matrix (ECM) proteins, serve a key role in the pathogenesis of MM (16) (Fig. 1). The adhesion that occurs between MM plasma cells and both BMSCs and ECM proteins has been well-established. These adhesions can influence the growth, proliferation, invasion and drug resistance of MM cells and cause angiogenesis and lytic bone lesions $(13,17)$. The very late antigen 4 (VLA-4), which is located on the MM plasma cell surface, mediates the binding between tumor cells and ECM proteins, including type I collagen and fibronectin, and can bind to BMSC vascular cell adhesion molecule-1 (VCAM-1). The tumor cells that adhere to BMSCs can stimulate numerous pathways, and result in the upregulation of cytokines, which regulate the cell, and antiapoptotic proteins (18), including interleukin-6 (IL-6), RANKL and Activin A $(19,20)$. The interaction between MM and BMSC cells can be mediated via the Notch-signaling pathway. The notch-signaling pathway in MM and BMSCs can be stimulated by the interaction with Notch-Notch ligand, and can lead to the secretion of IL-6, vascular endothelial growth factor (VEGF) and insulin-like growth factor 1 (IGF-1). Additionally, the adhesion of MM cells to BMSCs also induces $\mathrm{NF}-\kappa \mathrm{B}$-dependent transcription and IL-6 secretion. IL-6 promotes MM cell production and secretion of VEGF, and regulates malignant plasma cell apoptosis and OC differentiation (21). Conversely, the inhibition of $\mathrm{NF}-\kappa \mathrm{B}$ activity abrogates this response (22). It has been previously demonstrated that in patients with MM, exosomes may be released by BMSCs and transferred to MM cells, leading to MM progression and the induction of drug resistance $(23,24)$. Recently, a study has demonstrated that MM exosomes that are derived from BMSCs can promote BMSC growth and angiogenesis by modifying the BM microenvironment. This modification can increase MM cell proliferation, disease progression and interfere with drug resistance (25). Although the specific mechanism governing this remains unclear, these findings revealed that cell exosomes may be associated with the intercellular transfer of genetic information in clonal plasma cell disorders (24). Understanding MM cell exosomes and their associated miRNA may enable the discovery of a novel therapeutic strategy for the treatment of MM.

Angiogenesis and endothelial cells. BM angiogenesis is considered to indicate MM progression (6). BM samples from patients with MM have demonstrated that angiogenesis serves an important role in MM pathogenesis (26). BM angiogenesis is assessed using measurements of microvessel density (MVD). These results are compared with patients who have inactive disease or MGUS as MVD has been demonstrated to consistently increase in patients with progressive MM (27). In the BM, a mutual interaction of cells, cytokines and growth factors exists inside an intricate ecosystem, in which pericytes and endothelial cells survive and proliferate with fibroblasts, inflammatory cells and hematopoietic stem cells. The growth of malignant cells in the BM has been revealed to disrupt this balance, resulting in an increase in vascularity and tumor progression (28). The release of pro-angiogenic cytokines/molecules, including VEGF, basic-fibroblast growth factor (bFGF) and the cell surface matrix metalloproteinases (MMPs), from malignant plasma cells, BMSC and OCs, can cause angiogenesis $(29,30)$. VEGF can stimulate proliferation and chemotaxis in stromal cells via VEGF receptor-1, (VEGFR-1) and in endothelial cells (ECs) via VEGFR-2 (31). VEGFR-1 expression is common in MM cell lines and in patients with MM. The mutual interaction between VEGF and VEGFR-1 induces MM cell proliferation and facilitates VEGF secretion. VEGF enhances angiogenesis and also contributes to cell growth and survival by inducing IL-6 secretion (32). VEGF interacts with pro-angiogenic factor osteopontin (OPN), which is secreted by OCs, to induce osteoclastogenic activity and enhance vascular endothelial cell angiogenesis (33). OCs produce MMP-9, which has been demonstrated to be responsible for OC-induced angiogenesis (34). In MM, BM sinusoids allow MM cells to receive $\mathrm{O}_{2}$ and nutrients, and contribute to the removal of catabolites from the circulation (35). Through the paracrine and cell adhesion-mediated interactions between MM cells and BMSCs, elevated BM neovascularization promotes MM plasma cell proliferation, survival and drug resistance. This occurs when insufficient nutrients and $\mathrm{O}_{2}$ are delivered to MM cells, which causes the upregulation of numerous cytokines associated with angiogenic activity, including VEGF and bFGF. This has been supported by in vitro data that has demonstrated that the elevated proliferation of MM cell lines and primary MM cells can be triggered by both human umbilical vein endothelial cells, and endothelial cells originating in BM aspirate samples of patients with active MM (36).

Osteoclasts (OCs). Normal bone is composed of mineralized and organic components. In a normal BM microenvironment, osteocytes, OCs and OBs sustain homeostasis by maintaining a balance between bone formation and bone resorption. Osteocytes constitute the majority of all bone cells, and OCs and OBs constitute $<10 \%$ (37). The balance between the generation of new OBs and OCs is disrupted in MM, leading to the rapid development of bone lesions and bone resorption (38-40), which are the major primary clinical features of this disease (41). Patients with MM exhibit a decreased number of live osteocytes due to the presence of bone lesions, which may be involved in MM-induced OC formation (42). Bone destruction caused by osteoclast activation usually occurs close to MM plasma cells, and not in normal bone marrow. A number of cytokines are associated with osteoclast activation, including RANKL, interleukin-3 (IL-3) and MIP-1a (6). IL-3 expression significantly increases in patients with MM, and this can upregulate $\mathrm{OC}$ activity and inhibit osteogenic 


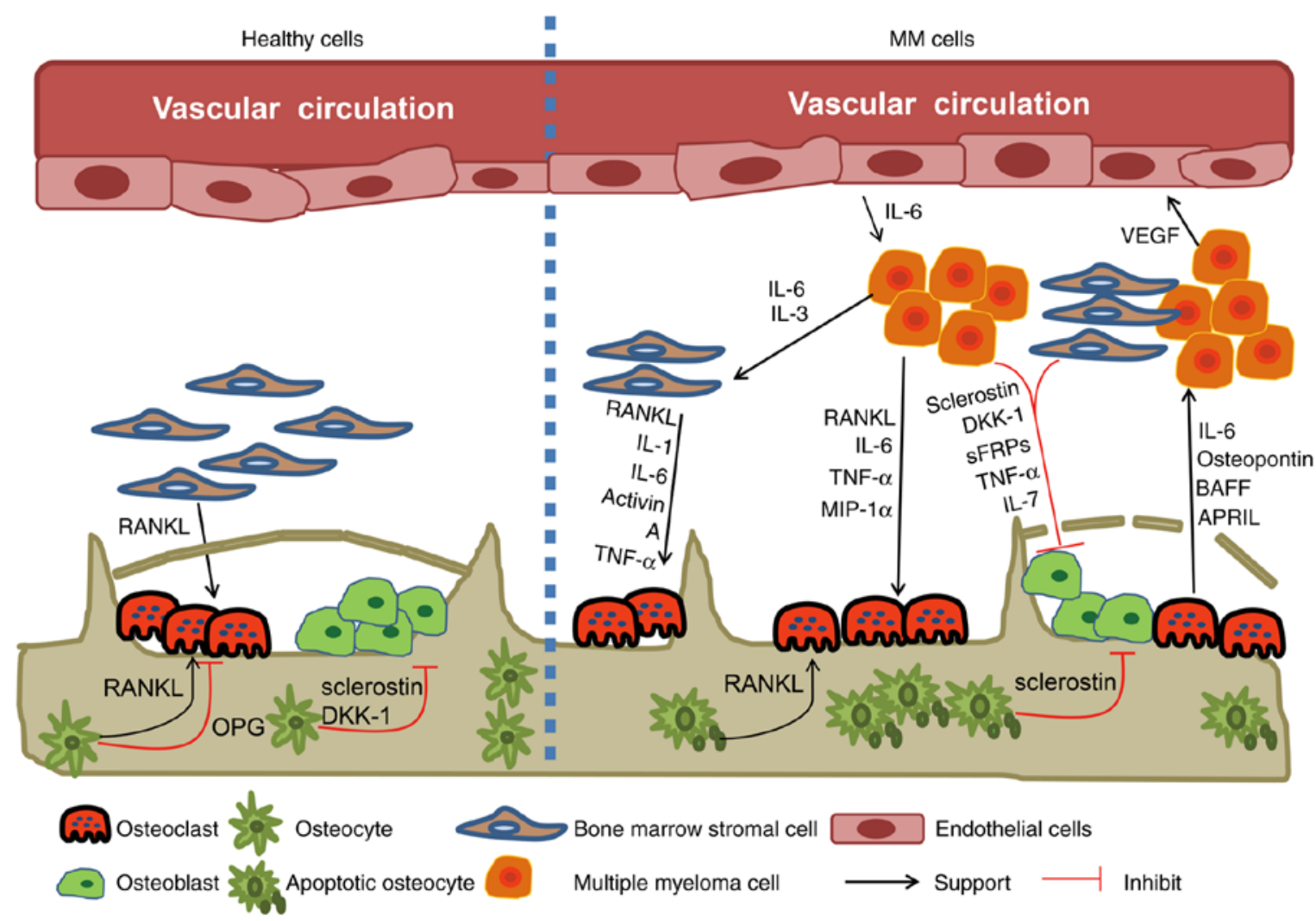

Figure 1. Interactions between MM cells and the BM microenvironment. In healthy individuals, an equilibrium exists between bone resorption and new bone deposition. Osteoblastic differentiation is inhibited by the secretion of Wnt signal inhibitors, DKK1 and sclerostin. OCs are also inhibited by OPG, which is secreted by osteocytes. As MM develops, MM cells induce osteoclastogenesis directly via the secretion of MIP-1 $\alpha$, IL-6, and indirectly via increased RANKL expression in stromal cells. OCs secrete anti-apoptotic cytokines, including IL-6, BAFF and APRIL. Endothelial cells also secrete IL-6, which stimulates MM cell proliferation. An increased number of MM cells can promote angiogenesis via the secretion of VEGF. MM, multiple myeloma; BM, bone marrow; DKK1, dikkopf 1; OCs, osteoclasts, OPG, osteoprotegerin; IL-6, interleukin-6; MIP, macrophage inflammatory protein; VEGF, vascular endothelial growth factor.

protein-2 (bone morphogenetic protein-2), which subsequently inhibits OB differentiation $(43,44)$. OCs produce OPN and IL-6, and the adhesion of OCs to MM plasma cells has been demonstrated to increase IL-6 production, a key growth factor involved in MM progression (45). Osteoclastic resorption induces the release of matrix-bound factors which promote the development of MM. This process has been named 'the vicious cycle' (46). Additionally, as a member of the tumor necrosis factor (TNF) family, RANK ligand has been associated with increased osteoclastogenesis, which is also involved with MM. In the bone marrow, the adhesion of MM plasma cells and neighboring BMSCs leads to an increase in RANKL expression. RANKL binding to its associated receptor indirectly increases osteoclast precursor cell activity, which increases OC differentiation via the c-Jun $\mathrm{N}$-terminal kinase pathway and NF- $\mathrm{KB}$ (47). Osteoprotegerin (OPG) is a soluble decoy receptor that is attracted to OBs and stromal cells. The RANKL and OPG molecules, which are mutually competitive receptors, serve an important role in the regulation of bone resorption (48). In patients with MM, higher RANKL expression and decreased OPG is exhibited in the bone marrow microenvironment, which leads to increased osteoclast activation and bone osteolysis. RANKL is the most important protein associated with the prolonged survival of MM plasma cells. This is due to RANKL inhibiting osteoclast apoptosis. It has been previously demonstrated that obstructing RANKL, with its soluble form, RANK, can accelerate bone loss and regulate tumor pressure in MM animal models (49). Recently, it has been reported that OC activity is associated with the excitation of resting MM cells in bone marrow. These results revealed that OCs may serve an important role in remodeling the terminal 'vicious cycle', as well as inducing tumor growth and increasing the possibility of relapse (50). Therefore, OCs are considered to be associated with tumor growth in MM (51).

Osteoblasts $(O B s)$. It is not yet clear what effects osteoblasts exhibit on MM cells. In patients with MM, OC proliferation and differentiation is inhibited due to bone cell abnormalities (52). Numerous factors are associated with the suppression of osteoblast activity and new bone growth, including the secretion of DKK1, soluble Wnt inhibitor frizzled-related protein 2 (sFRP-2) and transforming growth factor- $\beta$ (TGF- $\beta$ ) (53). DKK1, a Wnt-signaling antagonist, is secreted by MM cells and is overexpressed in patients with MM who exhibit lytic bone lesions (54). A previous study has demonstrated that the inhibition of DKK1 can reduce bone resorption and tumor burden in a severe combined immunodeficient 11-rabbit (SCID-rab) myeloma model (55). Additionally, OB differentiation has also been revealed to be suppressed by sFRP-2, which is produced by the majority of MM cells, including in RPMI8226 and U266 cell lines (56). A similar effect has been indicated subsequent to the induction of osteocyte overexpressing sclerostin (SOST) (57). However, intriguing findings are emerging in this field of research (58). Whether OBs are 
inhibitory or supportive in MM has been revealed to depend on the source of the MM cells (59). A previous study has indicated that OBs contributed to MM cell survival and growth, and also increased osteolysis development, which enhanced MM pathogenesis (19). The capacity of OBs to secrete IL-6 close to MM plasma cells may result in this phenomenon and promote increased bone resorption and MM cell proliferation (60). It has also been reported that OBs serve a key role in activating MM cell survival, and this may be due to the release of OPG inhibiting MM cell apoptosis, which is mediated by TNF-related apoptosis-inducing ligand (TRAIL) (61). Yaccoby et al demonstrated that the majority of MM plasma cells obtained from active MM patients, in triple-cultures with OBs+OCs, exhibited fewer viable cells compared with cells co-cultured with OCs and MM plasma cells alone. In myelomatous severe combined immunodeficiency (SCID) exhibited in mice implanted with fetal human bone (SCID-hu mouse model), OBs were revealed to inhibit tumor growth and increase bone mineral density (59). Overall, further research is required to determine an efficient method to target OBs and alter tumor cell survival and growth. This could be used as a novel therapeutic strategy in the treatment of patients exhibiting bone disease and tumor growth (46). Future research should aim to elucidate the mechanisms behind the interaction between OBs and MM plasma cells. Elucidating the mechanisms behind this interaction may support the potential use of osteoblastic mediators in the treatment of MM.

\section{Non-cellular compartment}

$I L-6$. The association between cytokines, proteolytic enzymes, chemokines and adhesion molecules provides survival signals that are used in MM plasma cells and are associated with the development of MM drug resistance. Among these, IL-6 has been reported to serve a key role in a variety of tumor activities, including cell migration, invasion, tumor growth, apoptosis, angiogenesis, the differentiation of tumor cells and inflammation or infection $(62,63)$. IL-6 was initially cloned as a B cell stimulating factor (BSF) and designated interferon $\beta 2$. IL-6 has been demonstrated to stimulate cytotoxic T cells and promote osteoclast precursor cells to differentiate into mature and active osteoclasts (64). In fact, the cellular sources of IL-6 in MM-infiltrated bone marrow are highly controversial, with their origin usually described as paracrine or autocrine (65). Initially, IL-6 was regarded as an autocrine factor produced by certain MM cells. However, the most recent consensus opinion is that the $\mathrm{BM}$ environment constitutes the main source of this cytokine (Fig. 2). Several recent studies have also confirmed the paracrine origin of IL-6 in murine models of plasmacytomas and MM $(66,67)$. Frank myeloma cells and myeloma progenitors in the BMME have been suggested to use two sources of IL-6 to promote tumor maintenance and proliferation in vivo (68). Numerous molecules and cytokines can upregulate the secretion of IL-6 derived from BMSCs. It has been previously reported that IL-6 can be detected in the supernatant of MM cells using stimulation with anti-CD40 antibody (69,70). Additionally, IL-1 $\beta$ has also been indicated to be a major cytokine that contributes to the production of BMSC IL- 6 via the paracrine loop, which promotes the growth and survival of MM cells (71). After binding to its receptor (IL-6R), IL-6 triggers the activation

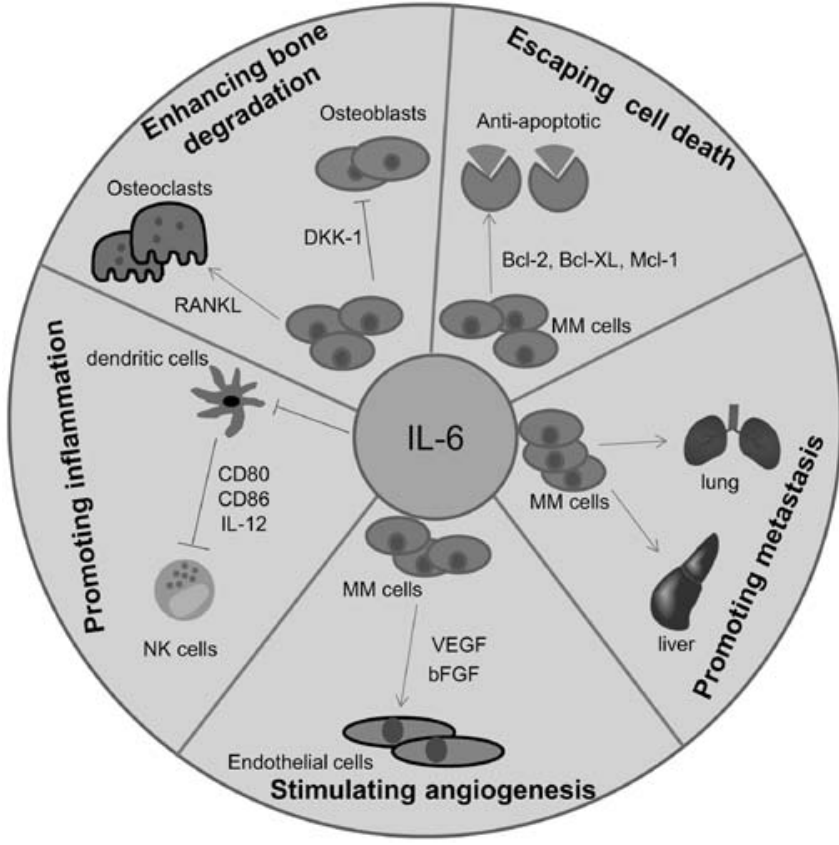

Figure 2. The roles of IL-6 in the BM microenvironment. IL-6 increases the expression of some survival proteins, including Bcl-2, Bcl-XL and Mcl-1, to decrease apoptosis in MM cells. IL-6 also serves a key role in promoting metastasis in a number of other organs, including the liver and lung. In MM cells, IL-6 upregulates VEGF via the JAK/STAT-3 signaling pathway to remodel vascular structure and increase angiogenesis. Additionally, IL-6 decreases the activity of NK cells by inhibiting the expression of CD80, CD86 and IL-12 in dendritic cells. IL-6 induces MM cell RANKL production and inhibits OB differentiation, via MM cell DKK-1 expression, to enhance bone degradation. IL-6, interleukin-6; BM, bone marrow; MM, multiple myeloma; VEGF, vascular endothelial growth factor; JAK, Janus kinase; STAT, signal transducer and activator of transcription; NK, natural killer; OB, osteoblast; DKK1, dikkopf1.

of the PI3K/Akt/mTOR (72-74) and Ras/Raf/MEK/Erk (35) signaling pathways. IL- 6 has also been revealed to serve a key role as an MM growth factor by stimulating IL-6R and triggering the phosphorylation of STAT3 via JAK1 (75). The Janus kinase (JAK)-signal transducer and activator of transcription (STAT) pathway was initially revealed to be associated with interferon- $\alpha$ (IFN- $\alpha$ ), IFN- $\gamma$ and IL-6-mediated downstream signaling (76). Blocking the IL-6R/STAT3 pathway has been indicated to induce apoptosis in MM cell line NCI-H929 (77). $\mathrm{NF}-\kappa \mathrm{B}$ has been demonstrated to be associated with cytokineand adhesion-mediated IL-6 upregulation. Therefore, the inhibition of NF- $\kappa \mathrm{B}$ can prohibit the secretion of IL-6 (78). In previous studies, it was suggested that the non-specific inhibition of IL- 6 could be performed due to its highly pleiotropic effects (with drugs including lenalidomide and associated immunomodulatory drugs), or IL-6 could be specifically targeted in MM and BMSCs (79). Presently, it is well-known that effective inhibition methods include the use of monoclonal antibodies (mAbs) to IL-6 (siltuximab) (80-82) or IL-6R (tocilizumab), or recombinant proteins, which act as IL-6R antagonists (83). Small molecules that inhibit the cellular IL-6 signaling pathway or cross-talked pathways in MM can also be used (84). Additional therapeutic treatments are performed using compounds, which either block the biochemical pathways that promote IL-6 signaling directly, or activate biochemical pathways which can inhibit IL-6 signaling indirectly (85). The 


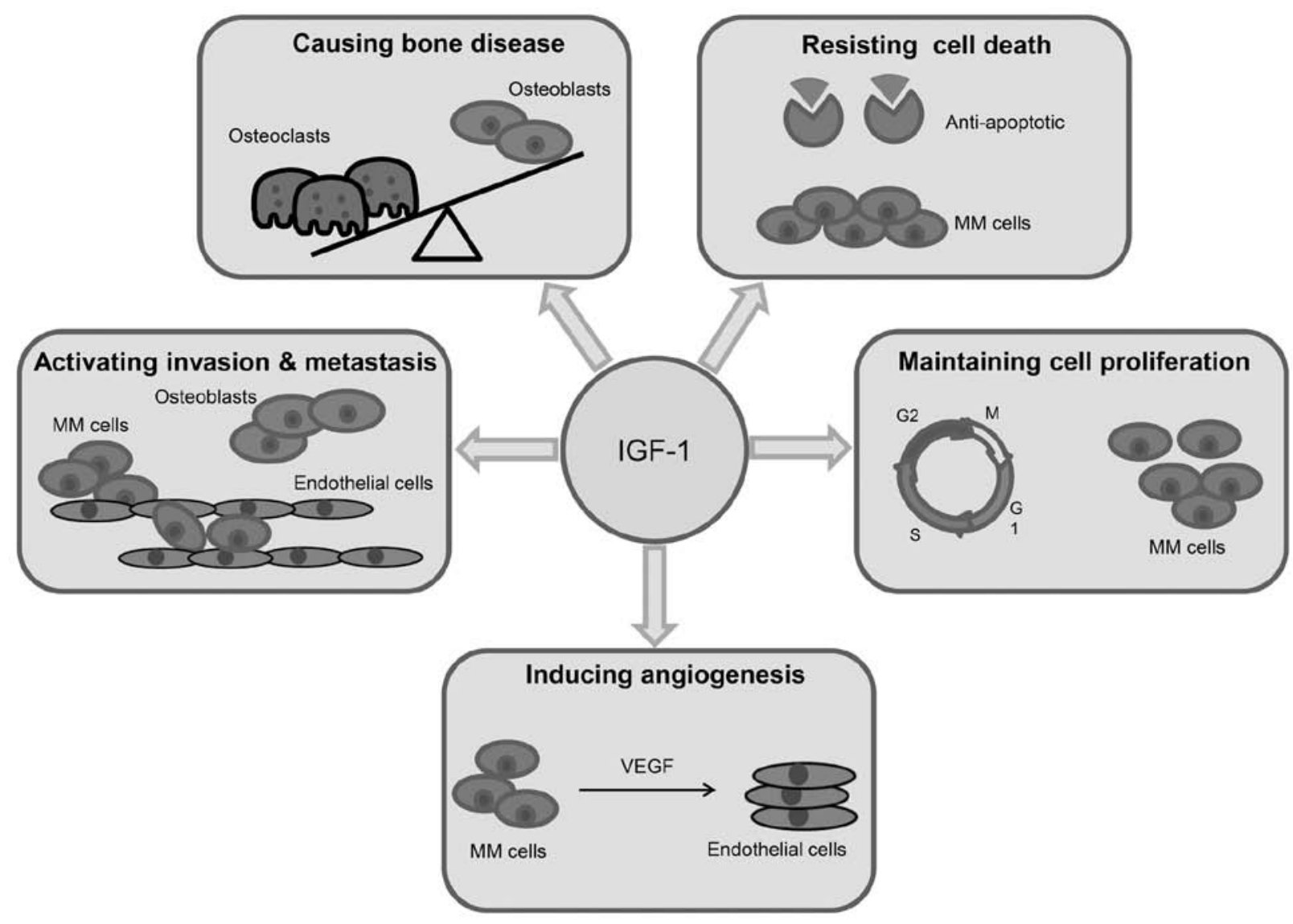

Figure 3. The roles of IGF-1 in MM-specific hallmarks. IGF-1 serves an important role in the homing process, and moves MM cells from the PB into the BM microenvironment. IGF-1 is also associated with bone disease through the promotion of OC activity and maturation, which subsequently inhibits OB activity. Insulin-like growth factor 1, IGF-1; MM, multiple myeloma; PB, peripheral blood; BM, bone marrow; OC, osteoclast; OB, osteoblast.

study of mice models is invaluable in providing key evidence for the potential preclinical use of IL-6-targeted therapies for MM treatment.

$I G F-1$. Within the past decade, the insulin-like growth factor (IGF) system has been demonstrated to serve a key role in the establishment and progression of MM $(86,87)$ (Fig. 3). It has been previously reported that IL-6 inhibition is not sufficient to induce effects in MM. Therefore, an increased interest has emerged into the IGF system, which can compensate IL-6 signaling and may induce the proliferation and survival of IL-6-independent MM cells (88). This suggests that IGF-1R inhibitors may contribute to the drug resistance exhibited, both in vitro and in vivo, to well-known anti-myeloma medicines $(89,90)$. In the extracellular environment, the IGF system is composed of six high-affinity insulin-like growth factor binding proteins (IGFBP1-6), IGF1, IGF2, IGF-1R and a minor free fraction of total IGF (91). The binding of free IGF to its receptor initiates a signaling cascade that results in the proliferation and viability of MM cells. In MM, IGF-1 is largely available in the BMME due to its secretion from BMSCs and OBs. It has been previously revealed that, through the activation of IGF-1R, IGF-1 serves an important role in MM cell growth, increases DNA synthesis and has been demonstrated to enhance the survival and proliferation of some MM cell lines. However, anti-IGF-IR blocking antibody use can inhibit the aforementioned effects $(92,93)$. A number of studies have indicated that MM cells exhibit high IGF-1 and IGF-1R expression and, through an autocrine cascade, IGF-1/IGF-1R signaling contributes to the survival, growth and drug resistance in MM cells $(86,94)$. Furthermore, in MM cell lines, it has been revealed that autocrine IGF-1 is an important self-clonogenic growth factor (95). Recent research has also demonstrated that IGF-1 can reverse the inhibition of cell proliferation induced by the knockdown of EEN. EEN, an endocytosis-regulating molecule, promotes the proliferation and viability of MM cells by stimulating IGF-1 secretion (96). In MM, the role of IGF-1/IGF-1R signaling in the inhibition of apoptosis and the induction of tumor cell proliferation occurs via activation of the PI3K/AKT and MAPK pathways (97). Which of these two activities (apoptosis or cell proliferation) is initiated depends on which pathway is induced. For example, apoptosis can be inhibited by IGF-IR through the activation of the PI3K/AKT pathway, which inhibits the ability of mitochondria to release cytochrome $c$. Subsequent to this, pro-apoptotic protein BAD is phosphorylated by activated AKT, separated from anti-apoptotic protein $\mathrm{Bcl}-2$ and sequestered by the adaptor protein 14-3-3, leading to the inhibition of apoptosis in PCM cells $(72,98)$. Additionally, IGF-1/IGF-1R is associated with MM cell proliferation, including migration, adhesion and invasion. These processes differentiate monoclonal malignant plasma cells in the BM microenvironment (99). IGF-1 serves a chemo-attractant role in murine 5T33MM cells and has been revealed to enhance cell adhesion to the extracellular matrix 
glycoprotein fibronectin in vitro by activating IGF-IR downstream targets, such as the PI3K/AKT pathway (100). IGF-1R is also upregulated in MM cells subsequent to interaction with the BMME (101). It has also been reported that enhanced IGF-1 signaling, through increased IGF-1 secretion and IGF-1R activation, is associated with bortezomib drug-resistance. This resistance may be overcome by inhibiting downstream targets such as PI3K and mTOR (90). IGF-1 signaling promotes the activation of AKT. However, the AKT signaling pathway is not the sole downstream kinase that can be activated by IGF-1. The MAPK pathway has been revealed to be activated by IGF-1 to promote MM proliferation in six MM cell lines (98). Conversely, one study reported that the MAPK pathway could only be activated in IL-6-dependent MM lines. Numerous downstream signaling pathways may also be activated by IGF-1, including the Janus kinase pathway (102). Therefore, further research is required to elucidate which additional signaling pathways lie downstream of IGF-1.

$V E G F$. An increase in BM vascularization has been demonstrated to be positively associated with an adverse prognosis in MM patients (103). New blood vessel growth enhances oxygen and nutrient transport to cells and can promote tumor growth. VEGF is a highly conservative homodimeric glycoprotein with a relative molecular mass of $45 \mathrm{kDa}$. VEGF is the only mitogen that is associated with endothelial cells (104). VEGF is a peptide growth factor that belongs to the platelet-derived growth factor (PDGF) superfamily, which exhibits high homology across species. VEGF has been previously described as a vascular permeability factor (VPF), and is now denoted VEGF-A (105). VEGF serves a key pro-angiogenic role in MM and is induced by MM cells and BMSCs (99). The secretion of VEGF can be stimulated by numerous cytokines and cell growth factors, including IL-6, bFGF, TGF- $\beta$ and tumor necrosis TNF- $\alpha$. VEGF serves a role in the formation of new blood vessels by binding to its receptors VEGFR-1 and VEGFR-2. This induces the survival, proliferation, migration and differentiation of BMSCs and ECs, through a number of signaling pathways, including Ras, GAP, PI3K/Akt, STAT and MEK/ERK (103). As aforementioned, angiogenesis is the formation of new vasculature from pre-existing vasculature, and has been demonstrated to be essential for tumor growth, invasion, and metastasis in a variety of cancer types (106). If the pro- and anti-angiogenic balance is broken and angiogenesis is favored, MGUS can turn into MM (107-109). VEGF has been revealed to be crucially implicated during osteoclastogenesis in MM (110). Research has also revealed that when VEGF binds to the VEGFR-1 receptor, which is expressed in OCs, OC cells are stimulated. However, OCs can also be activated indirectly, since MM cells can secrete VEGF subsequent to IL-6 stimulation (111). VEGF directly enhances osteoclastic bone resorption and the survival of mature OCs (33). Furthermore, VEGF is also correlated with high expression and activation of adhesion proteins and has been demonstrated to activate the secretion of proteases and ECM components, which can subsequently remodel ECM structures and modulate tumor cell-tumor cell and tumor cell-ECM interactions.

Exosomes. In recent years, rising evidence has emphasized the role of exosomes in the cross-talk between MM cells and the
BMME, and exosomes are now considered to be associated with cell to cell communication $(24,112,113)$. Exosomes, a sub-fraction of extracellular vesicles (EVs), range in size from 30-100 $\mathrm{nm}$. They transport a large variety of mRNAs, proteins and growth factors to target cells, and are secreted either via endocytosis, which occurs in MM cells and cells composing the BMME, or by direct fusion with the cell membrane (114-116). MicroRNAs (miRNAs), a class of small non-coding RNAs, are transported by exosomes and can suppress target gene expression at the post-transcriptional/translational level via hybridization with mRNA transcript sequences (117). It has also been reported that exosomes are associated with various biological processes, including inflammation, embryonic development, hematopoiesis, the immune response and tumorigenesis (118). In MM cells, upregulated miR-146a increases the expression and release of cytokines, including IL-6, CXCL1, IP-10 and CCL5, which enhance MM cell viability and migration (119). miR-146a has also been demonstrated to activate numerous signaling pathways, including NF- $\kappa$ B, Notch and JAK/STAT, and in turn, the Notch pathway contributes to the secretion of cytokines that are induced by miR-146a (120). Previous studies have indicated that MM cell-derived exosome treatment can increase the expression of OC-specific markers, including tartrate-resistant acid phosphatase (TRAP), cathepsin K (CTSK) and matrix metallopeptidase 9 (MMP9) (121). Amphiregulin (AREG), the epidermal growth factor receptor (EGFR) ligand, is expressed by $\mathrm{MM}$ cells and is associated with MM-derived exosomes, which participate in MM-induced osteoclastogenesis (122). AREG arises from the activation of the EGFR pathway and, subsequent to MM-derived exosome treatment, its presence is often confirmed by a significant increase in SNAIL mRNA, which is a downstream target of EGFR (122). In vitro studies have indicated that osteoblast differentiation and functionality can be inhibited by exosomes derived from 5TGM1 cells. This study also indicated that DKK1 expression was upregulated in MC3T3-E1 cells containing 5TGM1 exosomes (123). Aberrant angiogenesis has been demonstrated to be associated with exosomes in MM-infiltrated bone marrow (124). A previous study revealed that exosomes that are derived from hypoxia-resistant cells significantly increased angiogenesis, and exosomal miR-135b was considered to be a specific miRNA that is associated with chronic hypoxia (125). Numerous animal model studies have demonstrated that exosomes that are derived from normal BMSCs are effective in the treatment of cardiovascular disease (126) and kidney injury (127). Antitumor drugs, such as doxorubicin, could potentially be loaded into liposomes to improve osteosarcoma chemotherapy treatment (128). Additionally, liposomal doxorubicin could be used in conjunction with bortezomib or dexamethasone in the treatment of patients exhibiting MM (129). A recent study also revealed that in endothelial cells, miR-340 can inhibit angiogenesis via the hepatocyte growth factor/c-MET (HGF/c-MET) signaling pathway (130). Therefore, it can be expected that additional RNA or protein components that are associated with exosomes derived from MM cells or BMSCs exist, and are associated with the cell-cell communication among them. Research into exosomes provides important insights into the methods by which MM can be promptly diagnosed. Exosomal miRNAs, which are derived from young 
BMSCs, can be utilized in the formation of a novel strategy for MM treatment.

\section{Conclusion}

The present review investigated the strong interaction exhibited between MM cells and the surrounding BMME. The present review demonstrated that OBs, OCs, BMSCs and immune cells serve key roles in the promotion of MM cell growth and survival, inhibit autonomous or drug-induced MM cell apoptosis and therefore contribute to the development of osteolysis. Therefore, these cells should be considered in research into potential new treatment strategies for MM. The more research that investigates the interactions between healthy cells in the BMME, the better understanding will be gained into how MM disrupts the BMME. The development of novel MM treatment targets is ongoing. In recent years, the introduction of agents targeting MM cells and their interactions with the BMME, including proteasome inhibitors (bortezomib and carfilzomib) and immunomodulatory agents (thalidomide, lenalidomide and pomalidomide), has reduced mortality in patients with MM. Although bortezomib has been indicated to inhibit VEGF, IL-6 and IGF-1 secretion in BMSC and endothelial cells $(36,131)$, and the OB differentiation and $\mathrm{OC}$ apoptosis (132), further elucidation into the molecular mechanisms of MM-bone interactions and the MM niche are required to determine novel target approaches that exhibit beneficial effects on bone disease and MM tumor progression.

Currently, controversy exists as to whether a constant disease control approach should be pursued, which impacts patient quality of life and overall survival, or whether MM should be treated with an aggressive multidrug strategy that exhibits a complete recovery. Younger patients with poor prognosis may benefit more from the aggressive multidrug strategies as these patients are more likely to benefit long-term. However, for elderly, frail or non-high-risk patients who are newly diagnosed with MGUS, the treatment strategy should be to control the disease. This can be done by achieving stable renal function, which exhibits stable non-progression of bone disease, low toxic effects, high quality of life and increased survival rate. Future study should focus on developing combination therapies for a variety of patient subgroups to ensure patients in the low-risk stage or those who do not tolerate concentrated interventions will not be overtreated.

In conclusion, $\mathrm{MM}$ remains incurable and exhibits a complex pathophysiology. The interaction between MM plasma cells and BM has been demonstrated to serve a crucial role in the pathogenesis and progression of MM. The current standard treatment, and the majority of active anti-MM drugs, work against MM cells and BMME. Through targeting these diseased cells and their microenvironment, novel treatment strategies may be determined that can improve the outcome of this incurable blood cancer.

\section{Acknowledgements}

The authors would like to thank all Lab members, and CYG and YY for collecting literature and discussion.

\section{Funding}

The present study was supported by the National Natural Science Foundation of China (nos. 81670200, 81770220 and 81600177; to YY and CG); the 2016 Outstanding Youth Fund of Jiangsu Province BK20160048 (to YY); the Natural Science Foundation of Jiangsu Province BK20161041 (to CG); the National Key Research and Development Program-Precision Medicine sub-program 2016YFC0905900 (to YY); The Priority Academic Program Development of Jiangsu Higher Education Institutions for Chinese Medicine; the Innovation Team of Six Talent Peaks Project in Jiangsu Province TD-SWYY-015 (to CG).

\section{Availability of data and materials}

Not applicable.

\section{Authors' contributions}

YY, CG and ZF were involved in the conception of the review. JH and RW wrote the manuscript. JQ analyzed the data and plotted the graphs. CG and RW edited the manuscript. All authors have read and approved the final manuscript and agree to be accountable for all aspects of the research in ensuring that the accuracy or integrity of any part of the work are appropriately investigated and resolved.

\section{Ethics approval and consent to participate}

Not applicable.

\section{Patient consent for publication}

Not applicable.

\section{Competing interests}

The authors declare that they have no competing interests.

\section{References}

1. Rajkumar SV: Myeloma today: Disease definitions and treatment advances. Am J Hematol 91: 90-100, 2016.

2. Ferlay J, Soerjomataram I, Dikshit R, Eser S, Mathers C, Rebelo M, Parkin DM, Forman D and Bray F: Cancer incidence and mortality worldwide: Sources, methods and major patterns in GLOBOCAN 2012. Int J Cancer 136: E359-E386, 2015.

3. Landgren O, Kyle RA, Pfeiffer RM, Katzmann JA, Caporaso NE, Hayes RB, Dispenzieri A, Kumar S, Clark RJ, Baris D, et al: Monoclonal gammopathy of undetermined significance (MGUS) consistently precedes multiple myeloma: A prospective study. Blood 113: 5412-5417, 2009.

4. Kyle RA, Durie BG, Rajkumar SV, Landgren O, Blade J, Merlini G, Kröger N, Einsele H, Vesole DH, Dimopoulos M, et al: Monoclonal gammopathy of undetermined significance (MGUS) and smoldering (asymptomatic) multiple myeloma: IMWG consensus perspectives risk factors for progression and guidelines for monitoring and management. Leukemia 24: 1121-1127, 2010.

5. Kunisaki Y, Bruns I, Scheiermann C, Ahmed J, Pinho S, Zhang D, Mizoguchi T, Wei Q, Lucas D, Ito K, et al: Arteriolar niches maintain haematopoietic stem cell quiescence. Nature 502: 637-643, 2013.

6. Manier S, Sacco A, Leleu X, Ghobrial IM and Roccaro AM: Bone marrow microenvironment in multiple myeloma progression. J Biomed Biotechnol 2012: 157496, 2012. 
7. Crisan M and Dzierzak E: The many faces of hematopoietic stem cell heterogeneity. Development 143: 4571-4581, 2016.

8. Pang WW, Schrier SL and Weissman IL: Age-associated changes in human hematopoietic stem cells. Semin Hematol 54: 39-42, 2017.

9. Shiozawa Y, Pedersen EA, Havens AM, Jung Y, Mishra A, Joseph J, Kim JK, Patel LR, Ying C, Ziegler AM, et al: Human prostate cancer metastases target the hematopoietic stem cell niche to establish footholds in mouse bone marrow. J Clin Invest 121: 1298-1312, 2011.

10. Corcoran KE, Patel N and Rameshwar P: Stromal derived growth factor-1alpha: Another mediator in neural-emerging immune system through Tacl expression in bone marrow stromal cells. J Immunol 178: 2075-2082, 2007.

11. Shiozawa Y, Pedersen EA, Patel LR, Ziegler AM, Havens AM Jung Y, Wang J, Zalucha S, Loberg RD, Pienta KJ and Taichman RS: GAS6/AXL axis regulates prostate cancer invasion, proliferation, and survival in the bone marrow niche. Neoplasia 12: 116-127, 2010.

12. Chinni SR, Sivalogan S, Dong Z, Filho JC, Deng X, Bonfil RD and Cher ML: CXCL12/CXCR4 signaling activates Akt-1 and MMP-9 expression in prostate cancer cells: The role of bone microenvironment-associated CXCL12. Prostate 66: 32-48, 2006.

13. Kawano Y, Moschetta M, Manier S, Glavey S, Görgün GT, Roccaro AM, Anderson KC and Ghobrial IM: Targeting the bone marrow microenvironment in multiple myeloma. Immuno Rev 263: 160-172, 2015

14. Ribatti D, Nico B and Vacca A: Importance of the bone marrow microenvironment in inducing the angiogenic response in multiple myeloma. Oncogene 25: 4257-4266, 2006.

15. Ghobrial IM: Myeloma as a model for the process of metastasis: Implications for therapy. Blood 120: 20-30, 2012.

16. Anderson KC and Carrasco RD: Pathogenesis of myeloma. Annu Rev Pathol 6: 249-274, 2011.

17. Abdi J, Chen G and Chang H: Drug resistance in multiple myeloma: Latest findings and new concepts on molecular mechanisms. Oncotarget 4: 2186-2207, 2013.

18. Bianchi G and Munshi NC: Pathogenesis beyond the cancer clone(s) in multiple myeloma. Blood 125: 3049-3058, 2015.

19. Ribatti D, Moschetta M and Vacca A: Microenvironment and multiple myeloma spread. Thromb Res 133 (Suppl 2): S102-S106, 2014.

20. Lemaire M, Deleu S, De Bruyne E, Van Valckenborgh E, Menu E and Vanderkerken K: The microenvironment and molecular biology of the multiple myeloma tumor. Adv Cancer Res 110 19-42, 2011.

21. Wu Q, Zhou X, Huang D, Ji Y and Kang F: IL-6 enhances osteocyte-mediated osteoclastogenesis by promoting JAK 2 and RANKL activity in vitro. Cell Physiol Biochem 41: 1360-1369, 2017.

22. Hideshima T, Chauhan D, Schlossman R, Richardson P and Anderson KC: The role of tumor necrosis factor alpha in the pathophysiology of human multiple myeloma: Therapeutic applications. Oncogene 20: 4519-4527, 2001.

23. Wang J, Hendrix A, Hernot S, Lemaire M, De Bruyne E, Van Valckenborgh E, Lahoutte T, De Wever O, Vanderkerken K and Menu E: Bone marrow stromal cell-derived exosomes as communicators in drug resistance in multiple myeloma cells. Blood 124: 555-566, 2014.

24. Roccaro AM, Sacco A, Maiso P, Azab AK, Tai YT, Reagan M, Azab F, Flores LM, Campigotto F, Weller E, et al: BM mesenchymal stromal cell-derived exosomes facilitate multiple myeloma progression. J Clin Invest 123: 1542-1555, 2013.

25. Wang J, De Veirman K, Faict S, Frassanito MA, Ribatti D, Vacca A and Menu E: Multiple myeloma exosomes establish a favourable bone marrow microenvironment with enhanced angiogenesis and immunosuppression. J Pathol 239: 162-173, 2016.

26. Kumar S, Gertz MA, Dispenzieri A, Lacy MQ, Wellik LA Fonseca R, Lust JA, Witzig TE, Kyle RA, Greipp PR and Rajkumar SV: Prognostic value of bone marrow angiogenesis in patients with multiple myeloma undergoing high-dose therapy. Bone Marrow Transplant 34: 235-239, 2004.

27. Moschetta M, Mishima Y, Kawano Y, Manier S, Paiva B, Palomera L, Aljawai Y, Calcinotto A, Unitt C, Sahin I, et al: Targeting vasculogenesis to prevent progression in multiple myeloma. Leukemia 30: 1103-1115, 2016.

28. Vacca A and Ribatti D: Angiogenesis and vasculogenesis in multiple myeloma: Role of inflammatory cells. Recent Results Cancer Res 183: 87-95, 2011
29. Andreuzzi E, Colladel R, Pellicani R, Tarticchio G, Cannizzaro R, Spessotto P, Bussolati B, Brossa A, De Paoli P, Canzonieri V, et al: The angiostatic molecule Multimerin 2 is processed by MMP-9 to allow sprouting angiogenesis. Matrix Biol 64: 40-53, 2017.

30. Ria R, Reale A, De Luisi A, Ferrucci A, Moschetta M and Vacca A: Bone marrow angiogenesis and progression in multiple myeloma. Am J Blood Res 1: 76-89, 2011

31. Vacca A, Ria R, Ribatti D, Semeraro F, Djonov V, Di Raimondo F and Dammacco F: A paracrine loop in the vascular endothelial growth factor pathway triggers tumor angiogenesis and growth in multiple myeloma. Haematologica 88: 176-185, 2003.

32. Menu E, Kooijman R, Van Valckenborgh E, Asosingh K, Bakkus M, Van Camp B and Vanderkerken K: Specific roles for the PI3K and the MEK-ERK pathway in IGF-1-stimulated chemotaxis, VEGF secretion and proliferation of multiple myeloma cells: Study in the 5T33MM model. Br J Cancer 90: 1076-1083, 2004.

33. Tanaka Y, Abe M, Hiasa M, Oda A, Amou H, Nakano A, Takeuchi K, Kitazoe K, Kido S, Inoue D, et al: Myeloma cell-osteoclast interaction enhances angiogenesis together with bone resorption: A role for vascular endothelial cell growth factor and osteopontin. Clin Cancer Res 13: 816-823, 2007.

34. Cackowski FC, Anderson JL, Patrene KD, Choksi RJ, Shapiro SD, Windle JJ, Blair HC and Roodman GD: Osteoclasts are important for bone angiogenesis. Blood 115: 140-149, 2010.

35. Hideshima T, Mitsiades C, Tonon G, Richardson PG and Anderson KC: Understanding multiple myeloma pathogenesis in the bone marrow to identify new therapeutic targets. Nat Rev Cancer 7: 585-598, 2007.

36. Roccaro AM,Hideshima T, Raje N, Kumar S, Ishitsuka K, Yasui H Shiraishi N, Ribatti D, Nico B, Vacca A, et al: Bortezomib mediates antiangiogenesis in multiple myeloma via direct and indirect effects on endothelial cells. Cancer Res 66: 184-191, 2006.

37. Bonewald LF: The amazing osteocyte. J Bone Miner Res 26: 229-238, 2011.

38. Bataille R, Chappard D, Marcelli C, Dessauw P, Sany J, Baldet $\mathrm{P}$ and Alexandre C: Mechanisms of bone destruction in multiple myeloma: The importance of an unbalanced process in determining the severity of lytic bone disease. J Clin Oncol 7: 1909-1914, 1989

39. Delgado-Calle J, Bellido T and Roodman GD: Role of osteocytes in multiple myeloma bone disease. Curr Opin Support Palliat Care 8: 407-413, 2014

40. Kristensen IB, Christensen JH,Lyng MB, Møller MB, Pedersen L, Rasmussen LM, Ditzel HJ and Abildgaard N: Expression of osteoblast and osteoclast regulatory genes in the bone marrow microenvironment in multiple myeloma: Only up-regulation of Wnt inhibitors SFRP3 and DKK1 is associated with lytic bone disease. Leuk Lymphoma 55: 911-919, 2014.

41. Walker RE, Lawson MA, Buckle CH, Snowden JA and Chantry AD: Myeloma bone disease: Pathogenesis, current treatments and future targets. Br Med Bull 111: 117-138, 2014.

42. Giuliani N, Ferretti M, Bolzoni M, Storti P, Lazzaretti M, Dalla Palma B, Bonomini S, Martella E, Agnelli L, Neri A, et al: Increased osteocyte death in multiple myeloma patients: Role in myeloma-induced osteoclast formation. Leukemia 26: 1391-1401, 2012.

43. Ehrlich LA, Chung HY, Ghobrial I, Choi SJ, Morandi F, Colla S, Rizzoli V, Roodman GD and Giuliani N: IL-3 is a potential inhibitor of osteoblast differentiation in multiple myeloma. Blood 106: 1407-1414, 2005.

44. Lee JW, Chung HY, Ehrlich LA, Jelinek DF, Callander NS, Roodman GD and Choi SJ: IL-3 expression by myeloma cells increases both osteoclast formation and growth of myeloma cells. Blood 103: 2308-2315, 2004

45. Abe M, Hiura K, Wilde J, Shioyasono A, Moriyama K, Hashimoto T, Kido S, Oshima T, Shibata H, Ozaki S, et al: Osteoclasts enhance myeloma cell growth and survival via cell-cell contact: A vicious cycle between bone destruction and myeloma expansion. Blood 104: 2484-2491, 2004.

46. Croucher PI, McDonald MM and Martin TJ: Bone metastasis: The importance of the neighbourhood. Nat Rev Cancer 16: 373-386, 2016

47. Ehrlich LA and Roodman GD: The role of immune cells and inflammatory cytokines in Paget's disease and multiple myeloma. Immunol Rev 208: 252-266, 2005.

48. Emery JG, McDonnell P, Burke MB, Deen KC, Lyn S, Silverman C, Dul E, Appelbaum ER, Eichman C, DiPrinzio R, et al: Osteoprotegerin is a receptor for the cytotoxic ligand TRAIL. J Biol Chem 273: 14363-14367, 1998. 
49. Heath DJ, Vanderkerken K, Cheng X, Gallagher O, Prideaux M Murali R and Croucher PI: An osteoprotegerin-like peptidomimetic inhibits osteoclastic bone resorption and osteolytic bone disease in myeloma. Cancer Res 67: 202-208, 2007.

50. Lawson MA, McDonald MM, Kovacic N, Hua Khoo W, Terry RL, Down J, Kaplan W, Paton-Hough J, Fellows C, Pettitt JA, et al: Osteoclasts control reactivation of dormant myeloma cells by remodelling the endosteal niche. Nat Commun 6: 8983, 2015.

51. McDonald MM, Fairfield H, Falank C and Reagan MR: Adipose, bone, and myeloma: Contributions from the microenvironment. Calcif Tissue Int 100: 433-448, 2017.

52. Fu R, Liu H, Zhao S, Wang Y, Li L, Gao S, Ruan E, Wang G, Wang $\mathrm{H}$, Song $\mathrm{J}$ and Shao Z: Osteoblast inhibition by chemokine cytokine ligand 3 in myeloma-induced bone disease. Cancer Cell Int 14: 132, 2014

53. Gavriatopoulou M, Dimopoulos MA, Christoulas D, Migkou M Iakovaki M, Gkotzamanidou M and Terpos E: Dickkopf-1: A suitable target for the management of myeloma bone disease. Expert Opin Ther Targets 13: 839-848, 2009.

54. Moester MJ, Papapoulos SE, Löwik CW and van Bezooijen RL: Sclerostin: Current knowledge and future perspectives. Calcif Tissue Int 87: 99-107, 2010.

55. Zhou F, Meng S, Song H and Claret FX: Dickkopf-1 is a key regulator of myeloma bone disease: Opportunities and challenges for therapeutic intervention. Blood Rev 27: 261-267, 2013

56. Oshima T, Abe M, Asano J, Hara T, Kitazoe K, Sekimoto E Tanaka Y, Shibata H, Hashimoto T, Ozaki S, et al: Myeloma cells suppress bone formation by secreting a soluble Wnt inhibitor, sFRP-2. Blood 106: 3160-3165, 2005.

57. Delgado-Calle J, Anderson J, Cregor MD, Hiasa M, Chirgwin JM, Carlesso N, Yoneda T, Mohammad KS, Plotkin LI, Roodman GD and Bellido T: Bidirectional notch signaling and osteocyte-derived factors in the bone marrow microenvironment promote tumor cell proliferation and bone destruction in multiple myeloma. Cancer Res 76: 1089-1100, 2016.

58. Reagan MR, Liaw L, Rosen CJ and Ghobrial IM: Dynamic interplay between bone and multiple myeloma: Emerging roles of the osteoblast. Bone 75: 161-169, 2015

59. Yaccoby S, Wezeman MJ, Zangari M, Walker R, Cottler-Fox M, Gaddy D, Ling W, Saha R, Barlogie B, Tricot G and Epstein J: Inhibitory effects of osteoblasts and increased bone formation on myeloma in novel culture systems and a myelomatous mouse model. Haematologica 91: 192-199, 2006.

60. Mitsiades CS, McMillin DW, Klippel S, Hideshima T, Chauhan D, Richardson PG, Munshi NC and Anderson KC: The role of the bone marrow microenvironment in the pathophysiology of myeloma and its significance in the development of more effective therapies. Hematol Oncol Clin North Am 21 1007-1034, vii-viii, 2007.

61. Shipman CM and Croucher PI: Osteoprotegerin is a soluble decoy receptor for tumor necrosis factor-related apoptosis-inducing ligand/Apo2 ligand and can function as a paracrine survival factor for human myeloma cells. Cancer Res 63: 912-916, 2003.

62. Scheller J and Rose-John S: Interleukin-6 and its receptor: From bench to bedside. Med Microbiol Immunol 195: 173-183, 2006.

63. Suchi K, Fujiwara H, Okamura S, Okamura H, Umehara S, Todo M, Furutani A, Yoneda M, Shiozaki A, Kubota T, et al: Overexpression of Interleukin-6 suppresses cisplatin-induced cytotoxicity in esophageal squamous cell carcinoma cells Anticancer Res 31: 67-75, 2011.

64. Hong DS, Angelo LS and Kurzrock R: Interleukin-6 and its receptor in cancer: Implications for translational therapeutics. Cancer 110: 1911-1928, 2007

65. Kawano M, Hirano T, Matsuda T, Taga T, Horii Y, Iwato K, Asaoku H, Tang B, Tanabe O, Tanaka H, et al: Autocrine generation and requirement of BSF-2/IL- 6 for human multiple myelomas. Nature 332: 83-85, 1988.

66. Rosean TR, Tompkins VS, Olivier AK, Sompallae R, Norian LA, Morse HC III, Waldschmidt TJ and Janz S: The tumor microenvironment is the main source of IL- 6 for plasma cell tumor development in mice. Leukemia 29: 233-237, 2015.

67. Matthes T, Manfroi B, Zeller A, Dunand-Sauthier I, Bogen B and Huard B: Autocrine amplification of immature myeloid cells by IL-6 in multiple myeloma-infiltrated bone marrow. Leukemia 29: 1882-1890, 2015

68. Rosean TR, Tompkins VS, Tricot G, Holman CJ, Olivier AK, Zhan F and Janz S: Preclinical validation of interleukin 6 as a therapeutic target in multiple myeloma. Immunol Res 59: $188-202,2014$
69. Qi C, Tian S, Wang J, Ma H, Qian K and Zhang X: Co-expression of CD40/CD40L on XG1 multiple myeloma cells promotes IL-6 autocrine function. Cancer Invest 33: 6-15, 2015

70. Westendorf JJ, Ahmann GJ, Armitage RJ, Spriggs MK, Lust JA, Greipp PR, Katzmann JA and Jelinek DF: CD40 expression in malignant plasma cells. Role in stimulation of autocrine IL-6 secretion by a human myeloma cell line. J Immunol 152: 117-128, 1994.

71. Dinarello CA: Interleukin-1 in the pathogenesis and treatment of inflammatory diseases. Blood 117: 3720-3732, 2011.

72. Tu Y, Gardner A and Lichtenstein A: The phosphatidylinositol 3-kinase/AKT kinase pathway in multiple myeloma plasma cells: Roles in cytokine-dependent survival and proliferative responses. Cancer Res 60: 6763-6770, 2000.

73. Hideshima T, Nakamura N, Chauhan D and Anderson KC: Biologic sequelae of interleukin-6 induced PI3-K/Akt signaling in multiple myeloma. Oncogene 20: 5991-6000, 2001.

74. Hsu JH, Shi Y, Hu L, Fisher M, Franke TF and Lichtenstein A: Role of the AKT kinase in expansion of multiple myeloma clones: Effects on cytokine-dependent proliferative and survival responses. Oncogene 21: 1391-1400, 2002.

75. Sansone P and Bromberg J: Targeting the interleukin-6/Jak/stat pathway in human malignancies. J Clin Oncol 30: 1005-1014, 2012.

76. Matthes T, Manfroi B and Huard B: Revisiting IL-6 antagonism in multiple myeloma. Crit Rev Oncol Hematol 105: 1-4, 2016.

77. Monaghan KA, Khong T, Burns CJ and Spencer A: The novel JAK inhibitor CYT387 suppresses multiple signalling pathways, prevents proliferation and induces apoptosis in phenotypically diverse myeloma cells. Leukemia 25: 1891-1899, 2011.

78. Chauhan D, Kharbanda S, Ogata A, Urashima M, Teoh G, Robertson M, Kufe DW and Anderson KC: Interleukin-6 inhibits Fas-induced apoptosis and stress-activated protein kinase activation in multiple myeloma cells. Blood 89: 227-234, 1997.

79. Burger R: Impact of interleukin-6 in hematological malignancies. Transfus Med Hemother 40: 336-343, 2013.

80. Orlowski RZ, Gercheva L, Williams C, Sutherland H, Robak T, Masszi T, Goranova-Marinova V, Dimopoulos MA, Cavenagh JD, Špička I, et al: A phase 2, randomized, double-blind, placebo-controlled study of siltuximab (anti-IL-6 mAb) and bortezomib versus bortezomib alone in patients with relapsed or refractory multiple myeloma. Am J Hematol 90: 42-49, 2015.

81. San-Miguel J, Bladé J, Shpilberg O, Grosicki S, Maloisel F, Min CK, Polo Zarzuela M, Robak T, Prasad SV, Tee Goh Y, et al: Phase 2 randomized study of bortezomib-melphalan-prednisone with or without siltuximab (anti-IL-6) in multiple myeloma. Blood 123: 4136-4142, 2014.

82. Voorhees PM, Manges RF, Sonneveld P, Jagannath S, Somlo G, Krishnan A, Lentzsch S, Frank RC, Zweegman S, Wijermans PW, et al: A phase 2 multicentre study of siltuximab, an anti-interleukin- 6 monoclonal antibody, in patients with relapsed or refractory multiple myeloma. Br J Haematol 161: 357-366, 2013

83. Guo DJ, Han JS, Li YS, Liu ZS, Lu SY and Ren HL: In vitro and in vivo antitumor effects of the recombinant immunotoxin IL6(T23)-PE38KDEL in multiple myeloma. Oncol Lett 4: 311-318, 2012.

84. Younes A, Romaguera J, Fanale M, McLaughlin P, Hagemeister F, Copeland A, Neelapu S, Kwak L, Shah J, de Castro Faria S, et al: Phase I study of a novel oral Janus kinase 2 inhibitor, SB1518, in patients with relapsed lymphoma: Evidence of clinical and biologic activity in multiple lymphoma subtypes. J Clin Oncol 30: 4161-4167, 2012.

85. Garcia-Bates TM, Bernstein SH and Phipps RP: Peroxisome proliferator-activated receptor gamma overexpression suppresses growth and induces apoptosis in human multiple myeloma cells. Clin Cancer Res 14: 6414-6425, 2008.

86. Sprynski AC, Hose D, Caillot L, Réme T, Shaughnessy JD Jr, Barlogie B, Seckinger A, Moreaux J, Hundemer M, Jourdan M, et al: The role of IGF-1 as a major growth factor for myeloma cell lines and the prognostic relevance of the expression of its receptor. Blood 113: 4614-4626, 2009

87. Barretina J,Caponigro G,Stransky N, Venkatesan K, Margolin AA, Kim S, Wilson CJ, Lehár J, Kryukov GV, Sonkin D, et al: The cancer cell line encyclopedia enables predictive modelling of anticancer drug sensitivity. Nature 483: 603-607, 2012.

88. Mitsiades CS, Mitsiades NS, McMullan CJ, Poulaki V, Shringarpure R, Akiyama M, Hideshima T, Chauhan D, Joseph M, Libermann TA, et al: Inhibition of the insulin-like growth factor receptor-1 tyrosine kinase activity as a therapeutic strategy for multiple myeloma, other hematologic malignancies, and solid tumors. Cancer Cell 5: 221-230, 2004. 
89. Bieghs L,Lub S, Fostier K, Maes K, Van ValckenborghE, Menu E, Johnsen HE, Overgaard MT, Larsson O, Axelson M, et al The IGF-1 receptor inhibitor picropodophyllin potentiates the anti-myeloma activity of a $\mathrm{BH} 3$-mimetic. Oncotarget 5: 11193-11208, 2014.

90.Kuhn DJ, Berkova Z, Jones RJ, Woessner R, Bjorklund CC Ma W, Davis RE, Lin P, Wang H, Madden TL, Wei C, et al Targeting the insulin-like growth factor-1 receptor to overcome bortezomib resistance in preclinical models of multiple myeloma. Blood 120: 3260-3270, 2012.

91. Bieghs L, Brohus M, Kristensen IB, Abildgaard N, Bøgsted M, Johnsen HE, Conover CA, De Bruyne E, Vanderkerken K, Overgaard MT and Nyegaard M: Abnormal IGF-binding protein profile in the bone marrow of multiple myeloma patients. PLoS One 11: e0154256, 2016.

92. Jelinek DF, Witzig TE and Arendt BK: A role for insulin-like growth factor in the regulation of IL-6-responsive human myeloma cell line growth. J Immunol 159: 487-496, 1997.

93. Georgii-Hemming P, Wiklund HJ, Ljunggren $\mathrm{O}$ and Nilsson $\mathrm{K}$ : Insulin-like growth factor I is a growth and survival factor in human multiple myeloma cell lines. Blood 88: 2250-2258, 1996.

94. Chapuis N, Tamburini J, Cornillet-Lefebvre P, Gillot L, Bardet V, Willems L, Park S, Green AS, Ifrah N, Dreyfus F, et al: Autocrine IGF-1/IGF-1R signaling is responsible for constitutive PI3K/Akt activation in acute myeloid leukemia: Therapeutic value of neutralizing anti-IGF-1R antibody. Haematologica 95: 415-423, 2010

95. Chiron D, Maiga S, Surget S, Descamps G, Gomez-Bougie P Traore S, Robillard N, Moreau P, Le Gouill S, Bataille R, et al: Autocrine insulin-like growth factor 1 and stem cell factor but not interleukin 6 support self-renewal of human myeloma cells. Blood Cancer J 3: e120, 2013.

96. Huang EW, Xue SJ, Li XY, Xu SW, Cheng JD, Zheng JX, Shi H, Lv GL, Li ZG, Li Y, et al: EEN regulates the proliferation and survival of multiple myeloma cells by potentiating IGF-1 secretion. Biochem Biophys Res Commun 447: 271-277, 2014.

97. Vishwamitra D, George SK, Shi P, Kaseb AO and Amin HM Type I insulin-like growth factor receptor signaling in hematological malignancies. Oncotarget 8: 1814-1844, 2017.

98. Ge NL and Rudikoff S: Insulin-like growth factor I is a dual effector of multiple myeloma cell growth. Blood 96: 2856-2861,2000.

99. Bieghs L, Johnsen HE, Maes K, Menu E, Van Valckenborgh E, Overgaard MT, Nyegaard M, Conover CA, Vanderkerken K and De Bruyne E: The insulin-like growth factor system in multiple myeloma: Diagnostic and therapeutic potential. Oncotarget 7 : 48732-48752, 2016.

100. Vanderkerken K, Asosingh K, Braet F, Van Riet I and Van Camp B: Insulin-like growth factor-1 acts as a chemoattractant factor for 5T2 multiple myeloma cells. Blood 93: 235-241, 1999.

101. Asosingh K, Günthert U, Bakkus MH, De Raeve H, Goes E, Van Riet I, Van Camp B and Vanderkerken K: In vivo induction of insulin-like growth factor-I receptor and CD44v6 confers homing and adhesion to murine multiple myeloma cells. Cancer Res 60: 3096-3104, 2000.

102. Ogata A, Chauhan D, Urashima M, Teoh G, Treon SP and Anderson KC: Blockade of mitogen-activated protein kinase cascade signaling in interleukin 6-independent multiple myeloma cells. Clin Cancer Res 3: 1017-1022, 1997.

103. Podar K and Anderson KC: The pathophysiologic role of VEGF in hematologic malignancies: Therapeutic implications. Blood 105: 1383-1395, 2005.

104. Andersen NF, Vogel U, Klausen TW, Gimsing P, Gregersen H, Abildgaard $\mathrm{N}$ and Vangsted AJ: Vascular endothelial growth factor (VEGF) gene polymorphisms may influence the efficacy of thalidomide in multiple myeloma. Int J Cancer 131: E636-E642, 2012.

105. Senger DR, Galli SJ, Dvorak AM, Perruzzi CA, Harvey VS and Dvorak HF: Tumor cells secrete a vascular permeability factor that promotes accumulation of ascites fluid. Science 219 983-985, 1983.

106. Weis SM and Cheresh DA: Tumor angiogenesis: Molecular pathways and therapeutic targets. Nat Med 17: 1359-1370, 2011.

107. Asosingh K, De Raeve H, Menu E, Van Riet I, Van Marck E, Van Camp B and Vanderkerken K: Angiogenic switch during 5T2MM murine myeloma tumorigenesis: Role of CD45 heterogeneity. Blood 103: 3131-3137, 2004.

108. Bhutani M, Turkbey B, Tan E, Kemp TJ, Pinto LA, Berg AR, Korde N, Minter AR, Weiss BM, Mena E, et al: Bone marrow angiogenesis in myeloma and its precursor disease: A prospective clinical trial. Leukemia 28: 413-416, 2014.
109. Hose D, Moreaux J, Meissner T, Seckinger A, Goldschmidt H, Benner A, Mahtouk K, Hillengass J, Rème T, De Vos J, et al: Induction of angiogenesis by normal and malignant plasma cells. Blood 114: 128-143, 2009.

110. Taylor RM, Kashima TG, Knowles HJ and Athanasou NA VEGF, FLT3 ligand, PIGF and HGF can substitute for M-CSF to induce human osteoclast formation: Implications for giant cell tumour pathobiology. Lab Invest 92: 1398-1406, 2012 .

111. Terpos E, Christoulas D, Gavriatopoulou $M$ and Dimopoulos MA: Mechanisms of bone destruction in multiple myeloma. Eur J Cancer Care (Engl) 26, 2017.

112. Neviani P and Fabbri M: Exosomic microRNAs in the tumor microenvironment. Front Med (Lausanne) 2: 47, 2015.

113. Wang X, Lu H, Li T, Yu L, Liu G, Peng X and Zhao J: Krüppel-like factor 8 promotes tumorigenic mammary stem cell induction by targeting miR-146a. Am J Cancer Res 3: 356-373, 2013

114. Corrado C, Raimondo S, Chiesi A, Ciccia F, De Leo G and Alessandro R: Exosomes as intercellular signaling organelles involved in health and disease: Basic science and clinical applications. Int J Mol Sci 14: 5338-5366, 2013.

115. Raimondo S, Corrado C, Raimondi L, De Leo G and Alessandro R: Role of extracellular vesicles in hematological malignancies. Biomed Res Int 2015: 821613, 2015.

116. Zijlstra A and Di Vizio D: Size matters in nanoscale communication. Nat Cell Biol 20: 228-230, 2018.

117. Amodio N, Di Martino MT, Neri A, Tagliaferri P and Tassone P. Non-coding RNA: A novel opportunity for the personalized treatment of multiple myeloma. Expert Opin Biol Ther 13 (Suppl 1): S125-S137, 2013

118. Ohtsuka M, Ling H, Doki Y, Mori M and Calin GA MicroRNA processing and human cancer. J Clin Med 4 1651-1667, 2015.

119. De Veirman K, Wang J, Xu S, Leleu X, Himpe E, Maes K, De Bruyne E, Van Valckenborgh E, Vanderkerken K, Menu E and Van Riet I: Induction of miR-146a by multiple myeloma cells in mesenchymal stromal cells stimulates their pro-tumoral activity. Cancer Lett 377: 17-24, 2016.

120. Forloni M, Dogra SK, Dong Y, Conte D Jr, Ou J, Zhu LJ, Deng A, Mahalingam M, Green MR and Wajapeyee N: miR-146a promotes the initiation and progression of melanoma by activating Notch signaling. Elife 3: e01460, 2014.

121. Raimondi L, De Luca A, Amodio N, Manno M, Raccosta S, Taverna S, Bellavia D, Naselli F, Fontana S, Schillaci O, et al: Involvement of multiple myeloma cell-derived exosomes in osteoclast differentiation. Oncotarget 6: 13772-13789, 2015.

122. Raimondo S, Saieva L, Vicario E, Pucci M, Toscani D, Manno M, Raccosta S, Giuliani N and Alessandro R: Multiple myeloma-derived exosomes are enriched of amphiregulin (AREG) and activate the epidermal growth factor pathway in the bone microenvironment leading to osteoclastogenesis. J Hematol Oncol 12: 2, 2019.

123. Faict S, Muller J, De Veirman K, De Bruyne E, Maes K, Vrancken L, Heusschen R, De Raeve H, Schots R, Vanderkerken $\mathrm{K}$, et al: Exosomes play a role in multiple myeloma bone disease and tumor development by targeting osteoclasts and osteoblasts. Blood Cancer J 8: 105, 2018.

124. Kocemba KA, van Andel H, de Haan-Kramer A, Mahtouk K, Versteeg R, Kersten MJ, Spaargaren M and Pals ST: The hypoxia target adrenomedullin is aberrantly expressed in multiple myeloma and promotes angiogenesis. Leukemia 27 $1729-1737,2013$

125. Umezu T, Tadokoro H, Azuma K, Yoshizawa S, Ohyashiki K and Ohyashiki JH: Exosomal miR-135b shed from hypoxic multiple myeloma cells enhances angiogenesis by targeting factor-inhibiting HIF-1. Blood 124: 3748-3757, 2014.

126. Lai RC, Chen TS and Lim SK: Mesenchymal stem cell exosome: A novel stem cell-based therapy for cardiovascular disease. Regen Med 6: 481-492, 2011

127. Tomasoni S, Longaretti L, Rota C, Morigi M, Conti S, Gotti E, Capelli $\mathrm{C}$, Introna $\mathrm{M}$, Remuzzi $\mathrm{G}$ and Benigni A: Transfer of growth factor receptor mRNA via exosomes unravels the regenerative effect of mesenchymal stem cells. Stem Cells Dev 22: 772-780, 2013

128. Chi Y, Yin X, Sun K, Feng S, Liu J, Chen D, Guo C and Wu Z: Redox-sensitive and hyaluronic acid functionalized liposomes for cytoplasmic drug delivery to osteosarcoma in animal models. J Control Release 261: 113-125, 2017. 
129. Becker PS, Gooley TA, Green DJ,Burwick N,Kim TY,KojouriK, Inoue Y, Moore DJ, Nelli E, Dennie T and Bensinger WI: A phase 2 study of bortezomib, cyclophosphamide, pegylated liposomal doxorubicin and dexamethasone for newly diagnosed multiple myeloma. Blood Cancer J 6: e422, 2016.

130. Umezu T, Imanishi S, Azuma K, Kobayashi C, Yoshizawa S, Ohyashiki K and Ohyashiki JH: Replenishing exosomes from older bone marrow stromal cells with miR-340 inhibits myeloma-related angiogenesis. Blood Adv 1: 812-823, 2017.
131. Hideshima T, Mitsiades C, Akiyama M, Hayashi T, Chauhan D, Richardson P, Schlossman R, Podar K, Munshi NC, Mitsiades N and Anderson KC: Molecular mechanisms mediating antimyeloma activity of proteasome inhibitor PS-341. Blood 101: 1530-1534, 2003.

132. Chauhan D, Singh A, Brahmandam M, Podar K, Hideshima T, Richardson P, Munshi N, Palladino MA and Anderson KC: Combination of proteasome inhibitors bortezomib and NPI-0052 trigger in vivo synergistic cytotoxicity in multiple myeloma. Blood 111: 1654-1664, 2008. 